\title{
METHODOLOGICAL ASPECTS IN TRAINING BUSINESSPEOPLE: ENGLISH DECLARATIVE SENTENCES INTONATION CONTOURS IN BUSINESS NEGOTIATIONS
}

\author{
Elena Malyuga ${ }^{1}$, Svetlana Orlova ${ }^{1}$, Maria Ivanova ${ }^{2}$, Alex Krouglov ${ }^{3}$ \\ ${ }^{1}$ Peoples' Friendship University of Russia (RUSSIAN FEDERATION) \\ ${ }^{2}$ Maxim Gorky Institute of Literature and Creative Writing (RUSSIAN FEDERATION) \\ ${ }^{3}$ London Metropolitan University (UNITED KINGDOM)
}

\begin{abstract}
Today, the sphere of prosodic design of negotiation discourse remains relatively unexplored.

Declarative sentences usually prevail in practically any speech style. This is why this article considers the functional aspect of intonation contours inherent in English declarative sentences. In non-linguistic universities, future businesspeople learn about phonetic aspects of speech within a short timescale and with no natural linguistic setting whatsoever.

In the present study, we consider professionally oriented methods of teaching intonation in the process of organising pre-planned business negotiations.

This paper deploys the following methods of research: comparative analysis, electroacoustic (computer) analysis of verbalised speech, and mathematical-statistical analysis. Using these methods, we will be able to study speech visualisation data and ultimately outline the corresponding methodological principles critical for the training process.
\end{abstract}

Keywords: Intonation contours, declarative sentence, speech register, business negotiations, sense group.

\section{INTRODUCTION}

Participation in business negotiations can be viewed as a kind of public speech manipulation. Business negotiations are usually held to reach decisions pertaining to professional matters. The means of achieving professional goals have been the subject of various fields of research. Linguistics studies the tools of speech manipulation at all levels of language including the phonetic one.

In non-linguistic universities, future businesspeople learn about phonetic aspects of speech within a short timescale and with no natural linguistic setting whatsoever.

In our previous papers, we mostly considered the cases of prosodic construction of sentences, where each sentence was shaped by a single contour. However, in both dialogic and monologic utterances, sentence melody is often represented by a combination of a number of contours serving the purposes of intonational arrangement of sense groups (syntagms) that constitute naturally segmented parts of the sentence.

There is a number of reasons why business negotiations can be considered a productive domain to analyse:

- firstly, this speech register incorporates sense groups encapsulating various extensive sequences;

- secondly, we will be able to define the scope of the sense groups more explicitly;

- thirdly, this speech register is said to be characterised by relatively recurrent intonation contours;

- and finally, this speech situation appears to be especially engaging from the perspective of teaching future businesspeople.

The study aims to find effective ways of improving intonation training of future businesspeople. The currently established realistic principle governing the process of mastering of foreign language intonation patterns relies on the idea advocating proximity to normative pronunciation. Training intonation is generally about developing speech activity. 
The present study will provide an affirmative answer to a topical question: Is it possible to narrow down intonation of this particular speech register to a limited number of intonation contours? The cases that could not be interpreted based on the typical contours proved inconsiderable in number. All these cases were associated with a more or less vivid emotional colouring that, in a sense, presented a deviation from the general emotional background, which was defined as 'calm', 'categorical', and 'self-possessed'.

Most importantly, we will appeal to businesspeople as a specific professional cluster requiring specific phonetical training compatible with their vocational needs.

Intonational arrangement of polysyntagmatic speech primarily depends on its correct semantic segmentation, which poses a challenge to foreigners, especially when it comes to rapid reading of an unfamiliar text [1].

The types of monologic speech that usually deploy slower tempo as compared with dialogical speech (such as public lectures, professional presentations, etc.) are commonly characterised by an increased absolute duration of pauses between the syntagms, while their relevant duration remains unchanged: pauses registered in the middle of a sentence are typically twice shorter than those encountered at the end of the sentence [2].

Intonation should also be viewed as a powerful tool for emotions management in the course of negotiations. English intonation in the framework of business communication differs from the Russian intonation patterns we are familiar with. The Russian language is less emotional, but we also use different intonation in the conversation. We state something and give orders in an even tone, while requests are usually pronounced in a slightly higher pitch. An English-speaking businessperson is not necessarily an emotional person, it's just that he is used to the intonational patterns inherent in his native language and characterised by the use of rising and falling tones [3]. Intonation patterns used by Russian businesspeople may seem even and unemotional to their English-speaking partners, which is why it may appear that Russian businesspeople are bored with their interlocutors or that they are just plain arrogant.

The question of what intonation patterns should be used in the framework of business communication is a rather complex one. This depends on a number of factors, such as people's disposition and emotional state, background noise, the subject of negotiation, and even non-verbal signals [4]. With the most constructive negotiations, non-verbal signals are synchronised to the greatest extent possible and are similar with both partners [5]. But knowing this, people may influence the course of negotiations and synchronise with their interlocutors in a somewhat artificial manner. This is what we call tuning technique [5]. Doing so, business partners may quickly shift to the constructive phase of their negotiation.

\section{METHODOLOGY OF RESEARCH}

In this study, the main intonation contours inherent in English and Russian speech patterns are compared in the framework of negotiations as one of the key speech registers. Such comparison will be useful as a methodological and practical support in ensuring accent-free language mastery.

The issue of exemplary intonation (its norm or standard) should not be dealt with based on averaging of a large amount of statistical data, but should rather be resolved through a conscious choice of archetypical target models. In our case, such models are represented by intonation patterns used by a businessperson whose speech is considered accurate and expressive [6]. To that end, the material was recorded and analysed using Speech Analyzer - a professional computer software showing graphical representations of speech recordings.

In terms of their parameters, selected intonation contours basically coincide with the intonation contours that existing phonetic reference books describe as basic intonation contours of the corresponding languages.

Based on the analysis conducted, we can state that in terms of the speech register underlying the present study the general range of pitch alternation is practically the same with Russian and English languages.

The contours are presented in order of frequency from most to least frequently used. Some contours were so rare, they had to be discarded as irrelevant. These are contours such as High + Low Fall or Low + Low Fall, etc. 
Intonation contours most typical of the English and Russian languages were registered as follows.

Table 1. Intonation contours most typical of the English and Russian languages

\begin{tabular}{|c|c|}
\hline \multicolumn{1}{|c|}{ Intonation contours used in English } & Intonation contours used in Russian \\
\hline High + High Fall & Rise-Fall + Low Rise \\
\hline High + Low Rise & Mid + Rise-Fall \\
\hline High + Fall-Rise & Low + Low Rise \\
\hline Low + Low Rise & High + Fall-Rise \\
\hline Low + High Fall & High + Low Fall \\
\hline
\end{tabular}

Comparing English and Russian intonation contours, one will first of all notice that many of them demonstrate very similar composition [7]. This is especially typical in cases when the beginning of the contours is practically the same, while their final parts are somewhat different or vice versa.

\section{RUSSIAN AND ENGLISH INTONATION CONTOURS USED IN BUSINESS NEGOTIATIONS}

It seems appropriate to elaborate on similar intonation contours commonly used in both languages because in this case people are most heavily inclined to replace foreign language contours by those they are familiar with, i.e. those typically deployed in their mother tongue [8]. From a pedagogical point of view, it is advisable to draw particular attention to the differences in the intonation contours, for ignoring these differences may create an impression of a foreign accent in the course of communicative interaction [9]. In comparing similar contours, we shall resort to the results retrieved through computer-aided analysis.

Let us first compare the English contour High + Low Rise (which all phonetic reference books describe as a basic intonation contour used to construct non-terminal sense groups) with a similar Russian contour Rise-Fall + Low Rise. We should note that this intonation contour appears most frequently used in the speech of Russian businesspeople, while in the speech of British respondents it was outpaced by High + High Fall. Moreover, in terms of the frequency of use, these contours are proportioned 2:1. This fact undermines the status of High + Low Rise as a main intonation contour deployed to shape non-terminal syntagms.

Analysing random examples with the corresponding contours, we can confirm our observations with respect to their form.

The first pair of juxtaposed intonation contours actually reveals the same ending (thus, Russian Low Rise appears practically identical to the English Low Rise), while the difference between them lies in the opening and intermediate parts. The opening part, however, is also practically the same if we consider a monosyllabic word. If the first stressed word consists of two or more syllables, the melody of the post-tonic part of the word differs in English and Russian.

In the English language, the tone remains approximately at the same level [10] (tone pitch at the end of the word is never lower than the pitch registered at the beginning of the word), while in Russian the tone of the post-tonic part reveals a sharp fall so that a rather significant gap is registered between the onset and the end part of the word.

As to the melody of the words enclosed in between the first and the last word within the syntagm, in Russian they are pronounced low within a contracted range which is aurally perceived as a sequence of even low tones. In English, the melody of intermediate words generally shapes a downward scale [11].

Let us now compare the most frequent English contour High + High Fall with a similar Russian contour High + Low Fall which is ranked last in terms of the frequency of use. The examples below demonstrate that in this case the first stressed word is pronounced the same in both languages within a virtually even high tone. For example: 


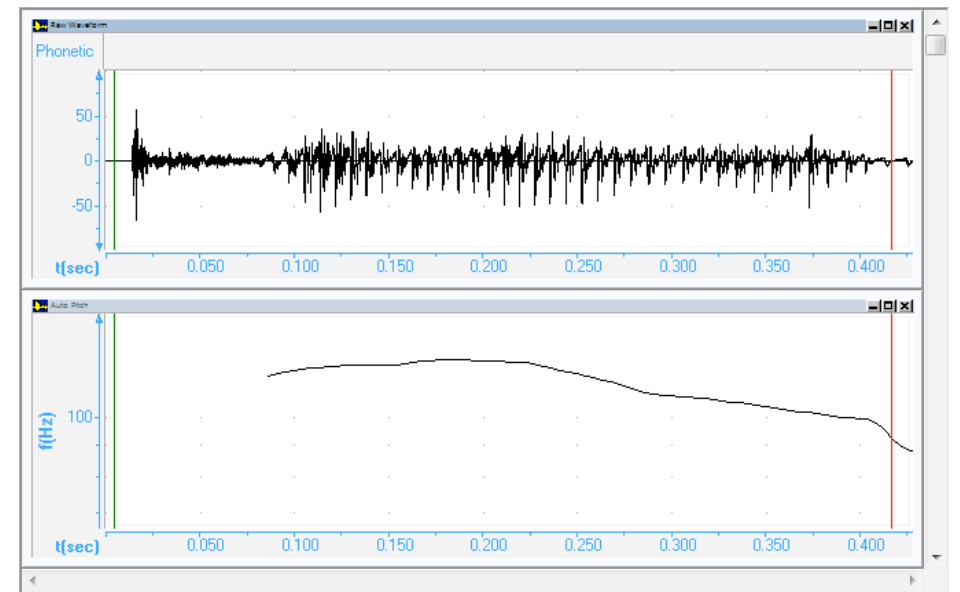

Figure 1. Comparative graph of English High + High Fall and Russian High + Low Fall intonation contours

Intermediate words reveal approximately the same melodic design as the one registered with the first pair of contours compared [12].

As to the last stressed word, in English the level marking the fall that concludes this contour is commonly approximately equal to the tone used to pronounce the first stressed word [13]. In Russian, on the contrary, the level of the last stressed syllable appears significantly below the level of the first stressed word.

The examples above allow us to specify another typical difference between English and Russian intonation contours of this type. In English, the final fall starts at the level exceeding the level of the preceding syllable [14]. In Russian, the preceding syllable appears above the stressed syllable that begins the final fall (i.e. it is higher in pitch).

For the English language, this correlation turns out more stable than the correlation of the first and last stressed syllables [15], which can be further illustrated through a number of examples. These examples show that the correlation of the last stressed syllable and the syllable preceding it is actually the only stable characteristic that can be used to differentiate the two types of falling tones - the High Fall and the Low Fall.
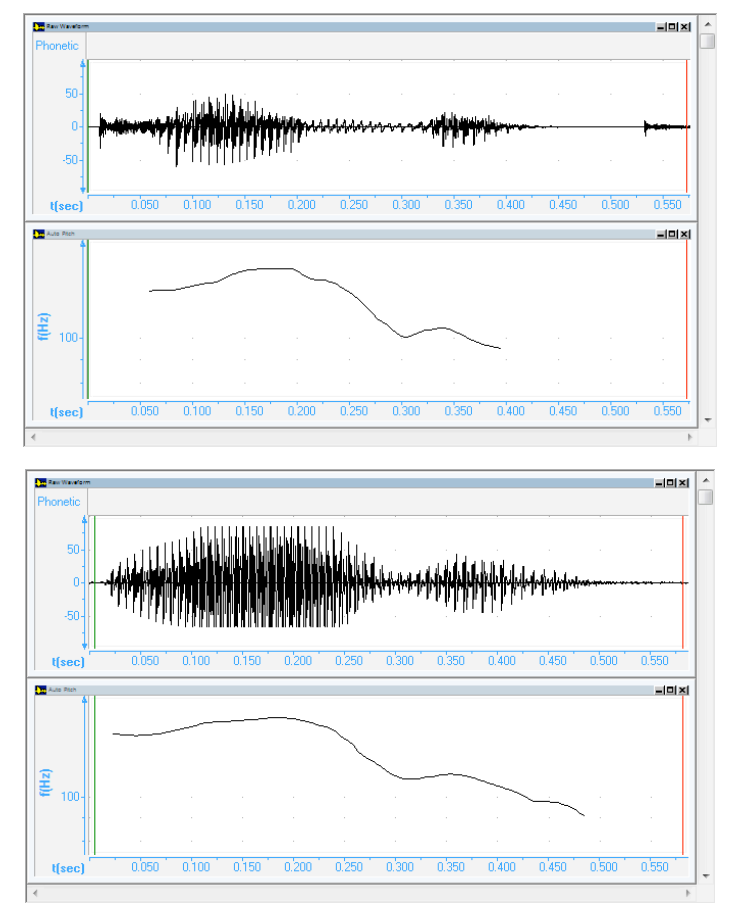

Figure 2. Comparative graph of High Fall and Low Fall intonation contours in English and Russian 
It should be noted that the correlation of the first and the last stressed syllables completing the fall is a rather rare case in Russian speech. In Russian, it is generally registered when the intermediate word receives special prominence in syntagms ending in a rising tone and thus completing the general contour of the sense group (High + Fall-Rise). This is because in Russian a high falling tone is associated with particular insistence on the part of the speaker. Therefore, if Russian speech appears infiltrated with the English contour High + High Fall, this might create an impression of excessive assertiveness or even aggression.

In order to make the speech more expressive, one should first of all underscore prosodic contrasts and oppositions [16]. This will facilitate speech perception. Such words as 'the other', 'another', 'secondly', 'different' highlight emphatic inclinations (high falling tone, falling-rising tone or a rising tone, etc.) [17]. In addition, there is a whole group of words referred to as emphatic that are used to underscore, intensify the meaning of the words that follow ('completely', 'absolutely', 'unbelievable', etc.) [18].

Besides, some words suggest the simplest kinds of imagery (for example, limit, finiteness, depth, etc.) that are well highlighted by the descending tone [18].

The contours we shall discuss at this point represent an entirely different case. English intonation contour High + Fall-Rise and Russian intonation contour Mid + Rise-Fall are specific contours intrinsic to the corresponding languages, because the combinations of the tones making up these contours comprise the tones inherent in one of these languages. The intonation contour High +Fall-Rise is part of the specific English tone - Fall-Rise [19], and the intonation contour Mid + Rise-Fall incorporates a common Russian tone - Rise-Fall.

Having analysed the examples of the intonation contours High +Fall-Rise, we can confirm our earlier observations concerning the Fall-Rise tone. In particular, this refers to our main conclusion about the preliminary tone increase as a characteristic trait of the Fall-Rise tone, as well as the inference suggesting that with dissyllabic words the fall element may be absent whatsoever if the second syllable begins with a voiceless consonant.

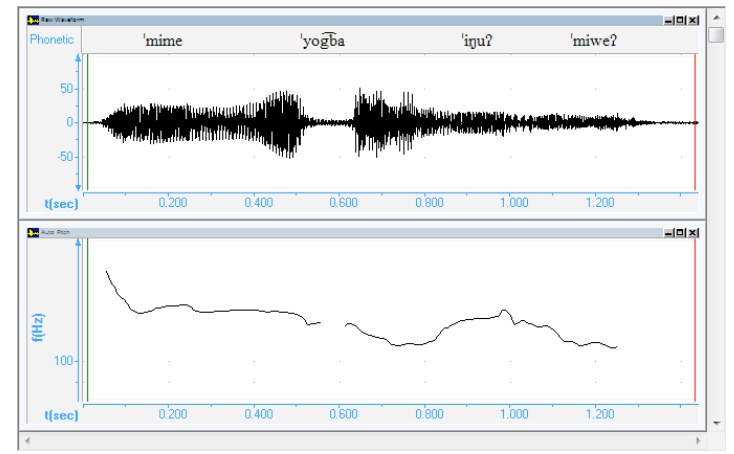

Figure 3. Comparative graph of English High + Fall-Rise and Russian Mid + Rise-Fall intonation contours

Reviewing the examples of the Russian intonation contour Mid + Rise-Fall, we were able to justify our observations made based on the acoustic analysis. The words preceding the last stressed word are indeed pronounced at an approximately the same middle level (therewith, melody fluctuations are insignificant and may well be characterised as a sequence of even tones); the stressed syllable reveals a slight rise of the tone within the high range, while the following stressed syllables within the same word are pronounced with gradual decrease down to the low level. Subsequent words, if any, are pronounced at a low level with gradual decrease.

This intonation contour is discussed in this paper to underline the fact that the tone of the half-stressed syllable (the word is somewhat in the shadow of the emphasised stress) is higher than the tone of the subsequent unstressed syllables. In other words, in this case there is no strong reduction taking place, whereas it would occur if the stressed syllable were accompanied by unstressed syllables only [20]. Strong reduction of stressed syllables in the Russian language shall be discussed further as we examine the way terminal syntagms are being shaped. 


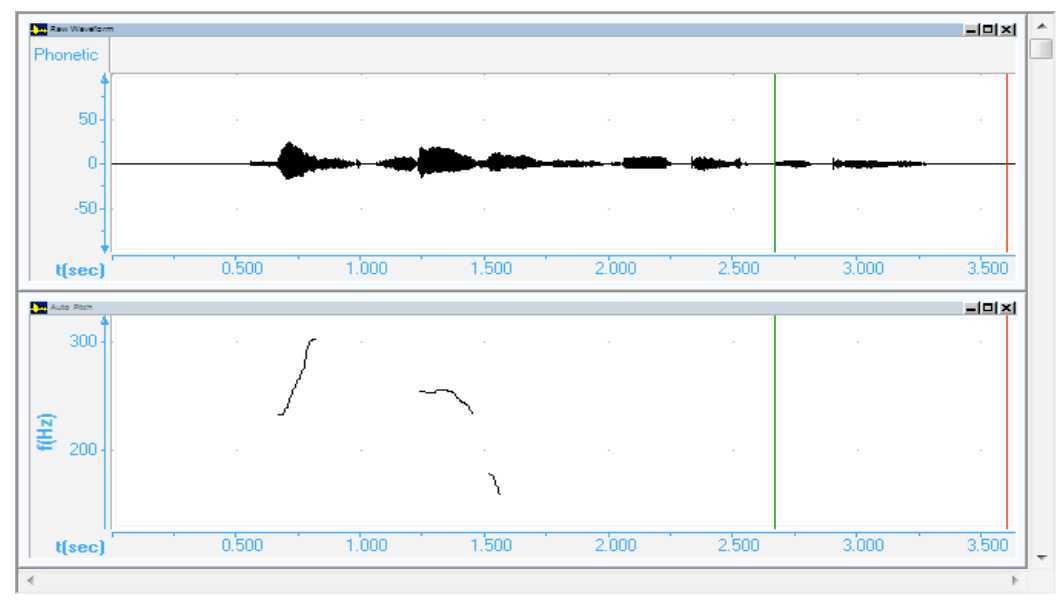

Figure 4. Comparative graph of English Mid-level and Russian Rise-Fall intonation contours

At the same time, we discover that not all implementations of this contour are characterised by the rise in the tone of the stressed syllable of the last stressed word within the syntagm. With polysyllabic words, Russian intonation contour Rise-Fall is very similar to the English Fall contour which might appear controversial, as we stated earlier that the Rise-Fall tone is not represented in English. However, upon closer inspection, one might discover a significant difference between the two tones, namely because the stressed syllable in Russian is pronounced within the upper border of the normal voice range, while in English the stressed syllable is primarily actualised at mid-level, which was also testified by ICT means at the stage of technical verification [21]. As a result, the interval between the points of maximum and minimum pitch within a single word in Russian is twice the corresponding interval in English. This fact of range divergence in the realisation of the stressed syllable in Russian and English with the general melodic similarity registered with the two languages can obviously be used in teaching Russian to the British, including matters of social and cultural differences [22].

Although the above implementations of the Rise-Fall tone reveal a somewhat nominal nature of the chosen term designating the tone, we believe that this name can be preserved for two reasons: 1) in monosyllabic words, this tone is realised regularly as an ascending tone; 2 ) in terms of functional application, this tone is associated with the incompleteness of the utterance and is thus equivalent to a simple rising tone.

\section{CONCLUSIONS}

Summing up, we can present the main conclusions following the analysis of English and Russian intonation contours used in business negotiations. Pursuant to the study, this speech register is characterised by relatively stable range, interval and temporal characteristics, which is why within this particular speech register intonation can be reduced to a limited number of alternating melodic contours.

Having compared the data related to English and Russian intonation, we were able to establish that from a formal point of view, these intonations have a lot in common within this speech register. Moreover, at the level of tones they appear even more alike than at the level of contours.

As to the terminal contours, the discrepancy between English and Russian appears to be more pronounced, which means that special care should be taken not to replace English intonation contours by their Russian counterparts.

With polysyllabic words, the rise goes on and extends to the subsequent syllables in English, while in Russian the tone exhibits a sharp fall with a simultaneous sharp decline in volume (sometimes reduced to whisper). Hence, the substitution of tones inherent in the two languages brings about a pronounced accent.

All in all, the issue of exemplary intonation (its norm or standard) should not be dealt with based on averaging of a large amount of statistical data, but should rather be resolved through a conscious choice of archetypical target models that should be taken into account while building up students' individual learning trajectories [23], [24]. In our case, such models were represented by intonation patterns used by businesspeople whose speech was considered accurate and expressive. 


\section{REFERENCES}

[1] G. Barker, Intonation patterns in Tyrolean German: An autosegmental-metrical analysis. Bern, Switzerland: Peter Lang, 2005.

[2] N. Braunschweiler, Automatic detection of prosodic cues. Dissertation, University of Konstanz, Germany, 2003.

[3] C. Brinckmann, "Improving prosody prediction for speech synthesis with and without symbolic prosody features," Phonus, vol. 10, pp. 124-139, 2006.

[4] M. Dalton, A. Chasaide, "Modelling intonation in three Irish dialects," in Proceedings of the 15th International Congress of Phonetic Sciences, Barcelona, pp. 1073-76, 2013.

[5] G. Demenko, A. Wagner, "The stylization of intonation contours," Proceedings of Prosody, vol. 6, pp. 204-219, 2006.

[6] G. Elordieta, P. Prieto, Prosody and meaning. Walter de Gruyter, 2013.

[7] C. Fery, Intonation and prosodic structure. Cambridge, UK: Cambridge University Press, 2016.

[8] E. Grabe, B. Post, "Intonational variation in the British Isles," Proceedings of Speech Prosody, vol. 2, pp. 343-346, 2002.

[9] C. Gussenhoven, "Intonation and interpretation: phonetics and phonology," Proceedings of Speech Prosody, vol. 2, pp. 47-57, 2002.

[10] C. Gussenhoven, The phonology of tone and intonation. Cambridge, UK: Cambridge University Press, 2004.

[11] D.J. Hirst, "The phonology and phonetics of speech prosody: Between acoustics and interpretation," Proceedings of Prosody, vol. 4, pp. 92-108, 2004.

[12] Y. Kawaguchi, I. Fonagy, T. Moriguchi, Prosody and syntax: Cross-linguistic perspectives. Amsterdam, the Netherlands: John Benjamins Publishing, 2006.

[13] K. Kohler, "Timing and communicative functions of pitch contours," Phonetica, vol. 62 (2-4), pp. 88-105, 2005.

[14] C. Lee, M. Gordon, Cross-linguistic perspective on meaning and intonation. Luxemburg: Springer Science \& Business Media, 2006.

[15] N. Mallik, Compact English prosody and figures of speech. New Delhi, India: Macmillan Publishers India Limited, 2009.

[16] T. Riad, C. Gussenhoven, Experimental studies in word and sentence prosody. Berlin, Germany: Walter de Gruyter, 2007.

[17] T. Riad, C. Gussenhoven, Typological studies in word and sentence prosody. Berlin, Germany: Walter de Gruyter, 2007.

[18] J. Romero-Trillo, Pragmatics and prosody in English language teaching. Luxemburg: Springer Science \& Business Media, 2012.

[19] G. Saintsbury, Historical manual of English prosody. Jakarta, Indonesia: Fb \& C Limited, 2015.

[20] J. Trouvain, U. Gut, Non-native prosody: phonetic description and teaching practice. Berlin, Germany: Walter de Gruyter, 2007.

[21] A. Krouglov, C. Dollerup, \& V. Appel, "Social and cultural differences," 3rd Language International Conference, Helsingor, Denmark, Teaching Translation and Interpreting 3, Vol. 16, New Horizons, Benjamins Translation Library, pp. 81-87, 1996.

[22] E. Malyuga, "Exploiting the potential of ICT: assessment of students' knowledge," SGEM2016. Bulgaria, Albena, Book 1, Vol. 3, pp. 319-326, 2016.

[23] E.N. Malyuga, "Individual-oriented training in professional communication teaching," ICERI2015 Proceedings. $8^{\text {th }}$ International Conference of Education, Research and Innovation. Seville, Spain, IATED, pp. 4807-4811, 2015. 
[24] A. Radyuk, E. Ponomarenko, E. Malyuga, "Prosodic peculiarities of discursive strategies in English economic discourse: the strategy of solution search," 4th International Multidisciplinary Scientific Conference on Social Sciences \& Arts SGEM2017, pp. 189-195, 2017. 